\title{
Bacteriophages as Antimicrobial Agents? Proteomic Insights on Three Novel Lytic Bacteriophages Infecting ESBL-Producing Escherichia coli
}

\author{
Sadika Dkhili, ${ }^{1,2}$ Miguel Ribeiro, ${ }^{3-5}$ Salma Ghariani, ${ }^{2}$ Houssem Ben Yahia, ${ }^{1,2}$ Mélanie Hillion, ${ }^{6,7}$ \\ Patricia Poeta, ${ }^{3,8}$ Karim Ben Slama, ${ }^{1,2}$ Michel Hébraud, ${ }^{6,7}$ and Gilberto Igrejas ${ }^{3-5, i}$
}

\begin{abstract}
With the emergence of multiresistant bacteria, the use of bacteriophages is gaining renewed interest as potential antimicrobial agents. The aim of this study was to analyze the structure of three lytic bacteriophages infecting Escherichia coli (SD1, SD2, and SD3) using a gel-based proteomics approach and the cellular response of this bacterium to phage SD1 infection at the proteome level. The combination of the results of 1-DE and 2-DE followed by mass spectrometry led to the identification of 3, 14, and 9 structure proteins for SD1, SD2, and SD3 phages, respectively. Different protein profiles with common proteins were noticed. We also analyzed phageinduced effects by comparing samples from infected cells to those of noninfected cells. We verified important changes in E. coli proteins expression during phage SD1 infection, where there was an overexpression of proteins involved in stress response. Our results indicated that viral infection caused bacterial oxidative stress and bacterial cells response to stress was orchestrated by antioxidant defense mechanisms. This article makes an empirical scientific contribution toward the concept of bacteriophages as potential antimicrobial agents. With converging ecological threats in the 21st century, novel approaches to address the innovation gaps in antimicrobial development are more essential than ever. Further research on bacteriophages is called for in this broader context of planetary health and integrative biology.
\end{abstract}

Keywords: Escherichia coli, bacteriophages, proteomics, oxidative stress, antioxidant defense, planetary health, antimicrobials

\section{Introduction}

$\boldsymbol{E}$ NTEROBACTERIACEAE ARE A LARGE FAMILY of gramnegative Bacilli, being Escherichia coli one of the most representative species of this family. These bacteria can be found in many ecosystems (soil, water, vegetation, and is part of the normal intestinal flora of humans and animals) (Ben Yahia et al., 2020). Some E. coli strains have developed mechanisms of pathogenicity; they are considered to be the most important opportunistic pathogens, which means that they can cause human and animal diseases (Ben Said et al., 2016). These diseases can be intestinal (diarrhea) or extraintestinal (septicemia, pneumonia, urinary tract infection, and meningitis) (Bolocan et al., 2016). $\beta$-Lactams are considered as the most powerful antimicrobial agents both in human and veterinary medicine.

However, resistance to this class of antibiotics has been reported to increase over time, especially in bacteria (Poeta

\footnotetext{
${ }^{1}$ Laboratoire des Microorganismes et Biomolécules actives, Faculté des Sciences de Tunis, Université de Tunis El Manar, Tunis, Tunisie. ${ }^{2}$ Institut Supérieur des Sciences Biologiques Appliquées de Tunis, Université de Tunis El Manar, Tunis, Tunisie.

${ }^{3}$ Department of Genetics and Biotechnology and ${ }^{4}$ Functional Genomics and Proteomics Unity, University of Trás-os-Montes and Alto Douro, Vila Real, Portugal.

${ }^{5}$ LAQV-REQUIMTE, Faculty of Science and Technology, University Nova of Lisbon, Lisbon, Portugal.

${ }^{6}$ University Clermont Auvergne, INRAE, UMR0454 Microbiology Digestive Environment Health (MEDiS), Saint-Genès Champanelle, France.

${ }^{7}$ INRAE, Metabolism Exploration Platform, Proteomic Component (PFEMcp), Saint-Genès Champanelle, France.

${ }^{8}$ Microbiology and Antibiotic Resistance Team (MicroART), Department of Veterinary Sciences, University of Trás-os-Montes and Alto Douro (UTAD), Vila Real, Portugal.

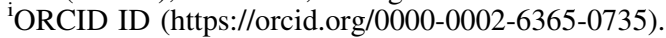


et al., 2009). Indeed, antimicrobials resistance (such as extended spectrum $\beta$-lactamases [ESBL]) is due to several factors, including the excessive use and uncontrolled abuse of antibiotics in human health, in veterinary medicine, for the needs of livestock and agriculture over time leading to an increase in bacterial resistance, in particular gram-negative bacteria such as E. coli (Odenthal et al., 2016; Törneke et al., 2015). Antibiotic resistance is considered today a worrying and evolving phenomenon and even a major global public health problem. The importance of the current situation urgently requires another bactericidal alternative of special and collective interest to tackle multiresistant bacteria (Dalmasso et al., 2016).

In this context, scientific research is geared more and more toward phage therapy, focusing on the discovery of new bacteriophages to fight bacterial diseases or to stop the dissemination of multiresistant bacteria (Hamdi et al., 2016). Bacteriophages are viruses that infect only bacteria and multiply within their specific hosts (Blasdel et al., 2017). They are considered to be the most abundant life form, it is estimated that there are around $10^{31}$ phage particles worldwide (Savalia et al., 2008; Wommack and Colwell, 2000). Nevertheless, before the investigation and the exploitation of bacteriophages in therapy, understanding the mechanisms of interactions between bacteriophages and their hosts is a preliminary and fundamental step to evaluate its safeness, effectiveness, and the potential to be applied.

Over the past decades, proteomics has become an important tool for the study of complex biochemical processes, the discovery of new proteins and the investigation of protein-protein interactions (Brötz-Oesterhelt et al., 2005). In this sense, phage proteomics can be an asset to the preclinical study of bacteriophages, delivering data about the interdependencies between viral proteins and host bacterial proteins during the infectious cycle. Also, the proteome is more dynamic and more complex than the genome, which prompts us to do a proteomic analysis to identify the protein composition of a given cell under a specific set of conditions (Brötz-Oesterhelt et al., 2005).

In this study, a gel-based proteomics approach was performed to study the structure of three novel lytic bacteriophages infecting ESBL-producing E. coli and the cellular response of this bacterium to phage infection at the proteome level.

\section{Materials and Methods}

\section{Bacterial strain and phage isolation}

The ESBL-producing E. coli $\mathrm{C} 3570$ was used as a host for three lytic bacteriophages. The host bacterial strain used for the phages isolation in this current study has been described and was preliminarily characterized by conventional biochemical methods and by specific polymerase chain reaction (PCR) (amplification of the uidA gene), and screened for the ESBL phenotype by double-disk synergy test in a previous publication (Ben Sallem et al., 2015). Phages SD1, SD2, and SD3 were isolated from wastewater samples from Tunisia, using a method previously described (Hamdi et al., 2016), and the phage purification step was repeated three times.

\section{Bacterial proteins extraction}

ESBL-producing E. coli $\mathrm{C} 3570$ cells were streaked on brain-heart infusion (BHI) plates and grown at $37^{\circ} \mathrm{C}$. Single colonies of this strain were transferred into an Erlenmeyer flask in $300 \mathrm{~mL}$ of stirred liquid BHI for 15 to $16 \mathrm{~h}$ to reach the highest point of the growth curve. Cells were harvested from the exponential phase in all experiments (An optical density $[\mathrm{OD}]_{540}=6$ corresponds to about $2-3 \times 10^{9} \mathrm{CFU} / \mathrm{mL}$ ).

The samples were handled in this way: only the bacteria and the bacteria infected with filtered phage. The cells were pelleted down at $10,000 \mathrm{~g}$ for $3 \mathrm{~min}$ at $4^{\circ} \mathrm{C}$. The pellet was resuspended in $4 \mathrm{~mL}$ of prewarmed phosphate-buffered saline $\mathrm{pH}$ 7.4. After new centrifugation (at $10,000 \mathrm{~g}$ for $3 \mathrm{~min}$ at $4^{\circ} \mathrm{C}$ ), the pellet was then resuspended in about $0.5 \mathrm{~mL}$ of $2 \%$ (w/v) sodium dodecyl sulfate (SDS), $250 \mathrm{mmol} / \mathrm{L}$ Tris at $\mathrm{pH}$ 9.5. The mixture was sonicated with an ultrasonic homogenizer (Vibra-Cell ${ }^{\mathrm{TM}}$ 75186) (four times for $10 \mathrm{sec}$ at $30 \%$ ). The disrupted cells were centrifuged $(14,000 \mathrm{~g})$ for $30 \mathrm{~min}$ at $4^{\circ} \mathrm{C}$. Then, $500 \mu \mathrm{L}$ of the supernatant were precipitated in icecold $1.5 \mathrm{~mL}$ of $20 \%(\mathrm{w} / \mathrm{v})$ trichloroacetic acid (TCA) in acetone during $1 \mathrm{~h}$ at $-20^{\circ} \mathrm{C}$. After centrifugation $(13,000 \mathrm{~g}$, $20 \mathrm{~min}, 4^{\circ} \mathrm{C}$ ), the pellet was resuspended in $200 \mu \mathrm{L}$ of icecold acetone and centrifuged again. This step was repeated at least three more times discarding the supernatant.

The pellet was left to dry overnight at room temperature. Finally, the dried pellet was solubilized in $200 \mu \mathrm{L}$ of solubilization buffer containing 4\% (w/v) 3-[(3-cholamidopropyl) dimethylammonio]-1-propanesulfonate (CHAPS), $7 \mathrm{~mol} / \mathrm{L}$ urea, $2 \mathrm{~mol} / \mathrm{L}$ thiourea, $1 \%$ (v/v) immobilized $\mathrm{pH}$ gradient (IPG) buffer, and $20 \mathrm{mmol} / \mathrm{L}$ 1, 4-dithiothreitol (DTT). Total solubilization was achieved using sonication (four times for $10 \mathrm{sec}$ at $30 \mathrm{sec}$ on ice). Protein concentration was assayed using the 2-D Quant Kit (GE Healthcare, Buckinghamshire, United Kingdom) following the manufacturer's instructions (Ribeiro et al., 2015).

\section{Phage concentration}

The phage concentration was performed as described elsewhere (Boulanger, 2009) with some modifications. In brief, to the bacteriophage filtrate was added sodium chloride $(\mathrm{NaCl}, 0.5 \mathrm{~mol} / \mathrm{L})$ and the mixture was incubated at $4{ }^{\circ} \mathrm{C}$ for $1 \mathrm{~h}$. This step promotes dissociation of phage particles from bacterial debris and is required for the next step of precipitation with polyethylene glycol (PEG). After incubation, the suspension was centrifuged at $10,000 \mathrm{~g}$ for $10 \mathrm{~min}$ at $4^{\circ} \mathrm{C}$. PEG 8000 (Sigma-Aldrich) was added to the supernatant to a final concentration of $10 \%(\mathrm{w} / \mathrm{v})$ and incubated overnight at $4^{\circ} \mathrm{C}$ to precipitate phage particles. Finally, phage particles were sedimented by centrifugation at $10,000 \mathrm{~g}$ for $20 \mathrm{~min}$ at $4^{\circ} \mathrm{C}$ and the supernatant was carefully discarded.

\section{Phage proteins extraction}

The pellet recovered from the concentration step was suspended in a solubilization buffer [1\% (w/v) SDS and $25 \mathrm{mM}$ Tris-HCl]. Total solubilization was achieved using sonication (four times for $10 \mathrm{sec}$ at 30\%) on ice. The sample was heated at $100^{\circ} \mathrm{C}$ for $3 \mathrm{~min}$. After centrifugation $(10,000 \mathrm{~g}$, $10 \mathrm{~min}, 4^{\circ} \mathrm{C}$ ), the supernatant was recovered. Protein was then precipitated using 2-D Clean-Up Kit (GE Healthcare Life Sciences) following the manufacturer's instructions and solubilized in $4 \%(\mathrm{w} / \mathrm{v})$ CHAPS, $7 \mathrm{~mol} / \mathrm{L}$ urea, $2 \mathrm{~mol} / \mathrm{L}$ thiourea, $1 \%(\mathrm{v} / \mathrm{v})$ IPG buffer, and $20 \mathrm{mmol} / \mathrm{L}$ DTT. The mixture was sonicated and centrifuged at $12,000 \mathrm{~g}$ for $5 \mathrm{~min}$ at $4^{\circ} \mathrm{C}$. Protein concentration was assayed using the 2-D Quant Kit (GE Healthcare) following the manufacturer's instructions (Ribeiro et al., 2015). 


\section{One-dimensional gel electrophoresis (1-DE)}

In brief, protein samples from ESBL-producing $E$. coli C3570 host strain, phages, and host bacterial cells mixed with the filtrated phage SD1 obtained as above-mentioned were solubilized in a buffer containing $2 \%$ (w/v) SDS, $40 \%$ glycerol, $10 \mathrm{mmol} / \mathrm{L}$ Tris- $\mathrm{HCl}$ at $\mathrm{pH} 8.0$, and $0.02 \%(\mathrm{w} / \mathrm{v})$ bromophenol blue and separated in a resolving gel using $12.52 \% \mathrm{~T}$ (total monomer percentage) and $0.97 \% \mathrm{C}$ (weight percentage of crosslinker). The 1-DE were stained with Coomassie Blue $\mathrm{R}-250$ for $24 \mathrm{~h}$ and then washed in water overnight. Coomassiestained gels were scanned with a flatbed scanner (Umax PowerLook 1100, Fremont, CA, USA) (Ribeiro et al., 2015).

\section{Two-dimensional gel electrophoresis (2-DE)}

Isoelectric focusing (IEF) of $\sim 300 \mu \mathrm{g}$ of protein was performed using an IPG strip of $\mathrm{pH} 4-7(13 \mathrm{~cm})$ on an Ettan ${ }^{\mathrm{TM}}$ IPGphor II ${ }^{\mathrm{TM}}$ system (Amersham Biosciences) using the conditions described elsewhere (Chibani-Chennoufi et al., 2004) and summarized as follows: a first step of active rehydration was performed at $50 \mathrm{~V}$ for $12 \mathrm{~h}$, followed by IEF at $500 \mathrm{~V}$ for $1 \mathrm{~h}$, a gradient up to $1000 \mathrm{~V}$ for $1 \mathrm{~h}$, a gradient up to $8000 \mathrm{~V}$ for $2 \mathrm{~h} 30 \mathrm{~min}$, and finally, $8000 \mathrm{~V}$ for $30 \mathrm{~min}$. Focused IPG strips were equilibrated twice for $15 \mathrm{~min}$ in equilibration buffer [(6 mol/L urea, 30\% (w/v) glycerol, $2 \%$ (w/v) SDS in $0.05 \mathrm{~mol} / \mathrm{L}$ Tris- $\mathrm{HCl}$ buffer $\mathrm{pH} 8.8$ )]. In the first equilibration step, $1 \%$ DTT was added to the original equilibration buffer and $4 \%$ iodoacetamide in the second step. Bromophenol blue was also added to both solutions.

The equilibrated IPG strips were gently rinsed with SDS electrophoresis buffer, blotted to remove excessive buffer, and then applied to SDS-polyacrylamide gels $(T=12.52 \%$, $C=0.97 \%$ ). After SDS-polyacrylamide gel electrophoresis (SDS-PAGE), the 2-DE gels were fixed in $40 \%$ (v/v) methanol/10\% (v/v) acetic acid solution for $1 \mathrm{~h}$ and then stained overnight in Coomassie Brilliant Blue G-250.

Excess stain was removed by rinsing the gels with $40 \%$ (v/v) methanol solution. Coomassie-stained gels were scanned with a flatbed scanner (Umax PowerLook 1100, Fremont, CA, USA) and the digitized images were analyzed using Lab Scanner Image Master 5.0 software (Amersham Biosciences; GE Healthcare) and Progenesis SameSpots v4.5 (Nonlinear Dynamics Limited, Newcastle, United Kingdom). Protein patterns were the result of triplicate protein extractions and three 2-DE replicates. The reference gels are shown (Ramos et al., 2016).

\section{Protein identification by mass spectrometry}

Selected 2-DE gel pieces and 1-DE bands were excised and prepared for tryptic digestion. In-gel protein digestion was performed as previously described (Ribeiro et al., 2020). 2 -DE spots were reduced with $10 \mathrm{mM}$ DTT and then they were alkylated with $55 \mathrm{mM}$ iodoacetamide. They were distilled with $25 \mathrm{mM}$ ammonium bicarbonate and 5\% acetonitrile for $15 \mathrm{~min}$, followed by another distillation with $25 \mathrm{mM}$ ammonium bicarbonate, $50 \%$ acetonitrile for $30 \mathrm{~min}$ two times. Spots were dehydrated with $100 \%$ Acetonitrile for $10 \mathrm{~min}$. After dehydration, the acetonitrile was removed, and the spots were dried in a SpeedVac for about $10 \mathrm{~min}$.

Then, $100 \mathrm{ng}$ of Trypsin (Promega) in $25 \mathrm{mM}$ Ammonium was added to each spot and incubated at $37^{\circ} \mathrm{C}$ overnight. Peptides were further extracted from the gel pieces by adding of Acetonitrile $100 \%$ to the digestion solution (final concentration of acetonitrile around 45-50\%) followed by sonication for $10 \mathrm{~min}$. The peptides containing solution was transferred to new tubes. Before nanoscale liquid chromatography coupled to tandem mass spectrometry (nanoLC-MS/ MS) analysis, the samples were dried in a SpeedVac for around $30-45 \mathrm{~min}$. They were sonicated in $12 \mu \mathrm{L}$ of trifluoroacetic acid (TFA) $0.05 \%$ for $10 \mathrm{~min}$ and transferred into vials. Mass spectrometry scans were performed using a LTQOrbitrap Velos, from Thermo Scientific, with resolution of 15,000 . MS was operated in positive ion. Spectra were recorded with $\mathrm{m} / \mathrm{z}$ range of 375-1400. MS/MS scans were acquired in Fourier transform mass spectrometry (FTMS) with resolution of 7500 . So, $5 \mu \mathrm{L}$ of sample were injected in precolumn (C18 PepMap300, $5 \mu \mathrm{m}, 300 \AA$, $300 \mu \mathrm{m} \times 5 \mathrm{~mm})$.

Then, the sample was separated in a separation Column Acclaim PepMap 100, C18, and $75 \mu \mathrm{m} \times 25 \mathrm{~cm}$ nanoViper (Thermo scientific) using the following conditions: $30 \mathrm{~min}$ run, a linear gradient from $4 \%$ to $40 \% \mathrm{~B}$ over $15 \mathrm{~min}$ and from $40 \%$ to $90 \% \mathrm{~B}$ through $1 \mathrm{~min}\left(\mathrm{~A}: \mathrm{H}_{2} \mathrm{O}, 0.1 \%\right.$ formic acid, $5 \%$ dimethylsulfoxide [DMSO]; B: acetonitrile, $0.1 \%$ formic acid, 5\% DMSO; C: $\mathrm{H}_{2} \mathrm{O}, 0.05 \%$ TFA). Proteins were identified using Mascot Daemon (v. 2.5.1) software and Mascot search algorithm. MS and MS/MS spectra were searched against a database containing 206,156 protein sequences retrieved from UniProt (date: February 26, 2020). The protein sequences were from E. coli, Escherichia phages as well as other bacteriophages.

The following MASCOT parameters were applied: precursor mass tolerance of $20 \mathrm{ppm}$, fragment tolerance of 0.5 Da, trypsin specificity with two missed cleavages, carbamidomethylation of cysteine, oxidation of methionine, and deamidation (NQ) were set as variable modification. False discovery rate (FDR) was adjusted to $1 \%$, and at least two peptides were necessary to consider protein identification.

\section{Statistical and image analysis}

To study the cellular response of the ESBL-producing E. coli C3570 host strain to phage SD1 infection at the proteome level, the Coomassie-stained gels were scanned and the digitized images were analyzed using Progenesis SameSpots v4.5 (Nonlinear Dynamics Limited) to identify bacterial proteins differentially expressed after phage infection stress. The two conditions were studied with triplicate protein extractions and 2-DE for each condition; Condition 1, control protein samples from noninfected $E$. coli $\mathrm{C} 3570$ host strain, and Condition 2, bacterial cells subjected to phage SD1 infection, were compared with each other, and through a statistical analysis using the SameSpots software, those spots with an analysis of variance (ANOVA) $p$-value $\leq 0.05$ and a FDR $q$-value $\leq 0.05$ were selected for further analysis by mass spectrometry. Figure 1 shows, as an example, the results obtained for spot 916.

\section{Results \\ Phage structural characteristics}

The structural protein composition of the three phages under study was initially made through the separation of protein bands by 1-DE and their further analysis and identification by nanoLC-MS/MS. The 1-DE analysis of SD1, SD2, and SD3 gave rise to 13,17, and 10 Coomassie-stained bands, respectively, ranging from 6.5 to $212 \mathrm{kDa}$. Of these, three 


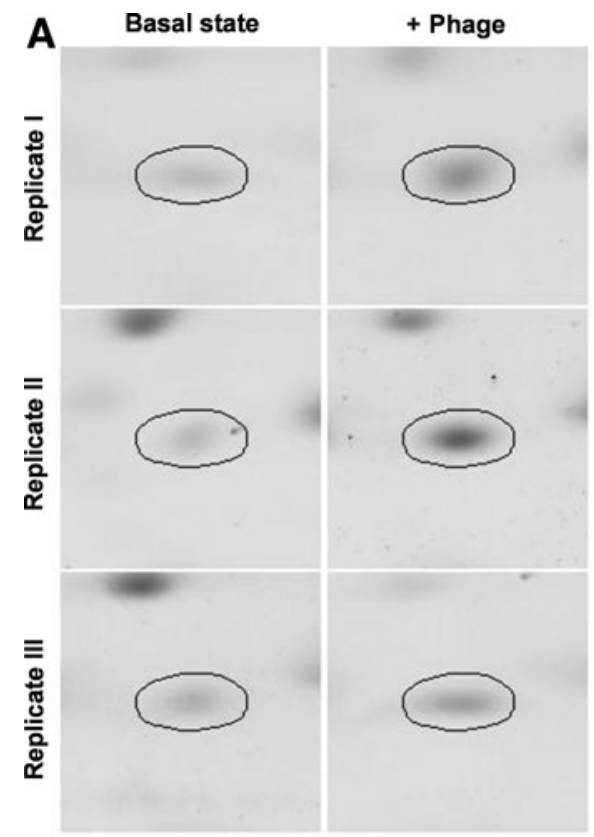

B

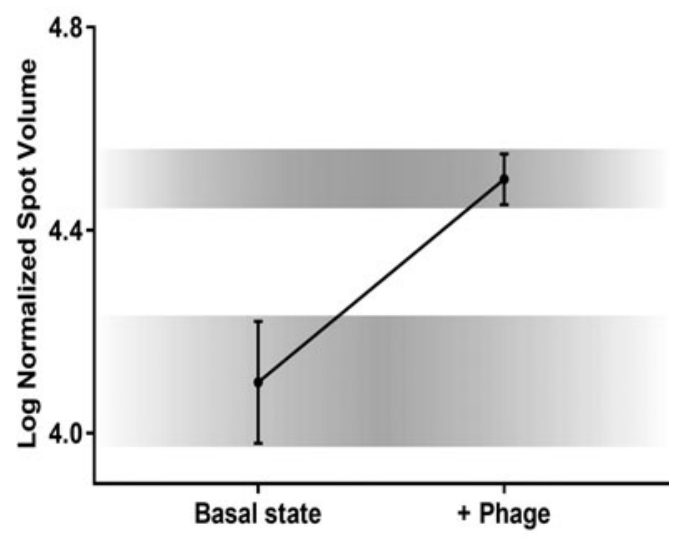

FIG. 1. Statistical image analysis. The results obtained for spot 916 , as an example, showing one replicate for the different conditions under study: condition 1 (bacteria) and condition 2 (bacteria infected with the filtrated phage SD1) (A). Normalized spot volumes used for the calculation of abundance changes (B).

structural proteins were successfully identified for each phage (SD1, SD2, and SD3) (Fig. 2A and Table 1). For SD1, sequence coverage ranges from $17 \%$ to $71 \%$; Major capsid protein, Tail sheath monomer, and Putative baseplate wedge tail fiber connector were identified (Fig. 2A and Table 1).

Regarding SD2, the sequence coverage was similar to that obtained for SD1 (24-64\%), the RNA polymerase ADPribosylase, Major capsid protein, and Putative baseplate wedge tail fiber connector were identified. With a sequence coverage of 25-56\%, major capsid protein, the Peptidase S74 domain containing protein, and the Putative long tail fiber were identified in SD3 bacteriophage (Fig. 2A and Table 1). The most abundant protein for phages SD1 and SD2 was the Major capsid protein, while for phage SD3, they were the Peptidase S74 domain-containing protein and Putative long tail fiber.

Some bacterial proteins were also identified in some bands. To further analyze the proteome of the bacteriophages, we performed 2-DE before the analysis by mass spectrometry. The different proteins identified by this approach are listed in Table 2 and Figure 2 B-D, which gather information about the accession number, molecular weight, Mascot score, sequence coverage, the number of significant unique sequences, and the predicted function of the proteins.

The use of $\mathrm{pH}$ 4-7 IPG strips resulted in a well-spread display of protein spots, which made spot excision and image identification more accurate. From the 2-DE profile of the phage SD1, it was possible to identify three distinct proteins, namely the Tail sheath monomer, the Capsid vertex protein, and the Major capsid protein, with a sequence coverage ranging from $42 \%$ to $54 \%$ (Table 2 and Fig. 2B).

The analysis of phage SD2 detected 14 structural proteins with a sequence coverage ranging from $32 \%$ to $69 \%$, including proteins of Dc2, RNA polymerase ADP-ribosylase, Thymidine kinase, Putative long tail fiber proximal subunit, Major capsid protein, Tail sheath monomer, Capsid vertex protein, Putative baseplate wedge subunit and tail pin, Baseplate wedge subunit, Putative tail fiber protein, Inhibitor of prohead protease, Prohead core scaffold protein, Portal protein, and the Fibritin_C domain-containing protein (Table 2 and Fig. 2C). For SD3 phage, nine structural proteins were detected with a sequence coverage ranging from $50 \%$ to $74 \%$. These proteins included uncharacterized protein, Tail tube protein, DarA, Putative baseplate wedge tail fiber connector, Tail sheath monomer, Capsid vertex protein, Major capsid protein, Structural protein, and the Putative major head protein (Table 2 and Fig. 2D).

During extraction, the use of reducing agents can result in the separation of different subunits of the identified protein, which despite corresponding to different spots are part of the same protein (Ribeiro et al., 2020). In the 2-DE gels of protein extracts from the three phages, different spots corresponding to the same protein are broadly distributed across the gel, with different isoelectric points and molecular weights probably due to posttranslational modifications affecting molecular mass and/or isoelectric point (Roberts et al., 2004) (Fig. 2). For SD2 proteins, the Putative long tail fiber was identified with two molecular masses of 49.9 and $136.5 \mathrm{kDa}$ (Table 2 and Fig. 3B).

For SD3 proteins, the Major capsid protein comes in two alternative forms of 37.7 and $56.5 \mathrm{kDa}$. Two alternative forms for the Tail tube protein were identified with molecular mass of 17 and $18.3 \mathrm{kDa}$ (Table 2 and Fig. 2D). Probably, the two alternative forms of Putative long tail fiber of SD2 phage are two subunits of the same protein. These two proteins split into minor subunits, which were previously stabilized by noncovalent interactions (Bishop et al., 1974). Same case for the two proteins of SD3 phage that have different alternative forms (the Major capsid protein and the Tail tube protein). Possibly, theses subunits are parts of a bigger protein. In addition, the physical proximity between the excised spots can also explain these results (Ribeiro et al., 2020). 

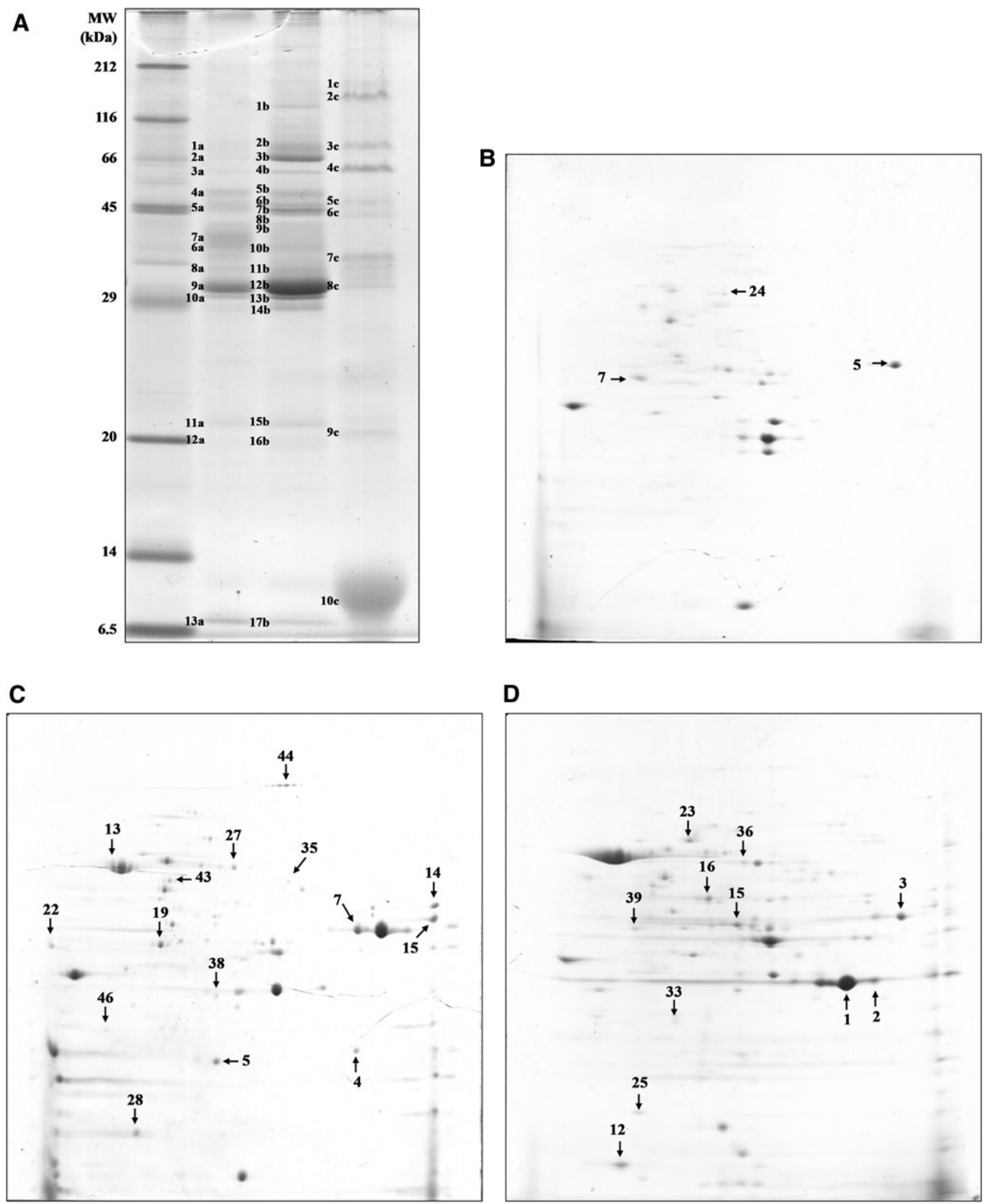

FIG. 2. (A) 1-DE pattern of SD1, SD2, and SD3 phages and the bands analyzed by nanoLC-MS/MS-based peptide mass fingerprinting (Table 1). Sizes in (kDa) of the protein molecular weight marker are shown on the left of the gel. 2-DE spot pattern of proteins from phages SD1 (B), SD2 (C), and SD3 (D) and the spots analyzed by nanoLC-MS/MS-based peptide mass fingerprinting (Table 2). 


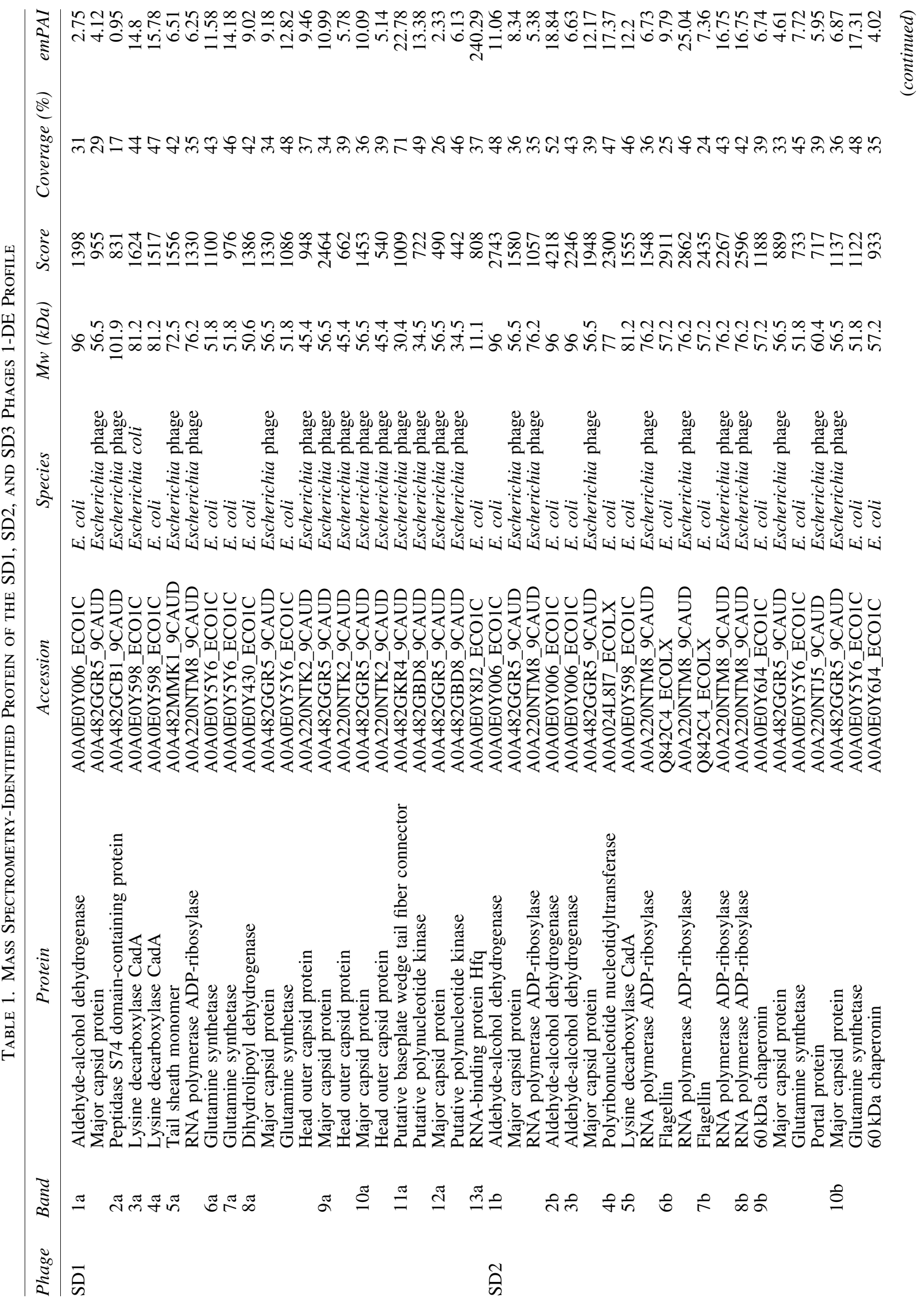




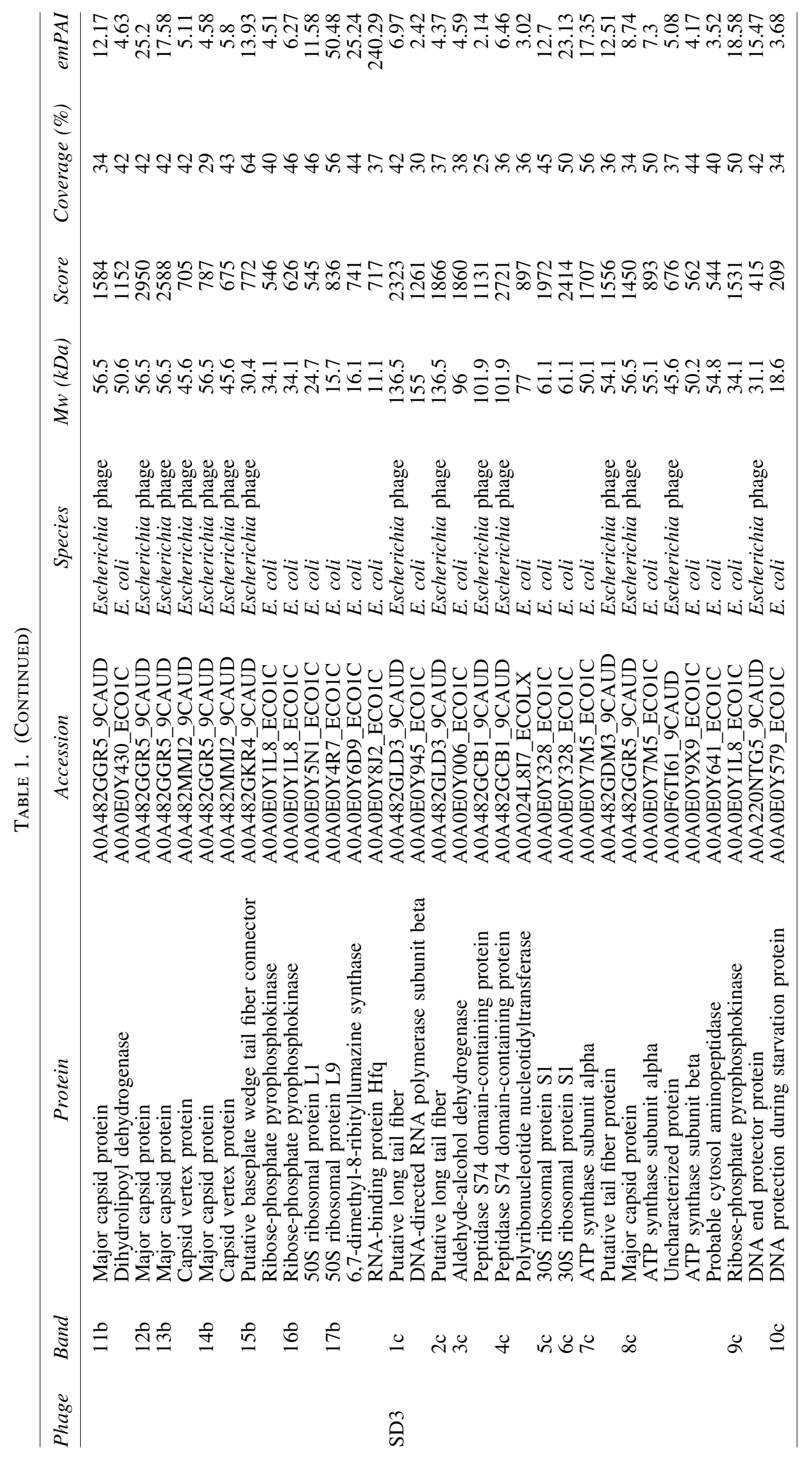




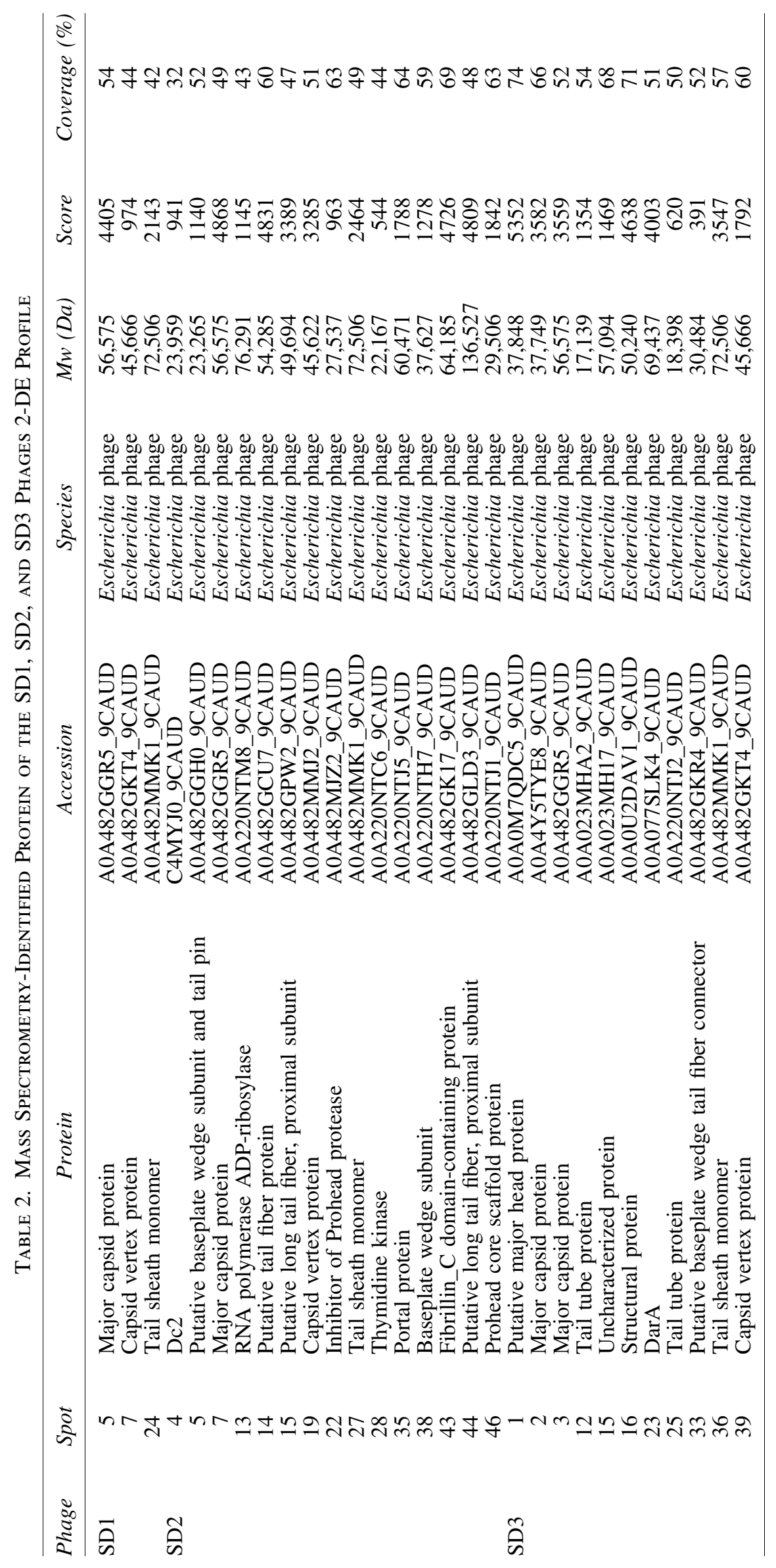




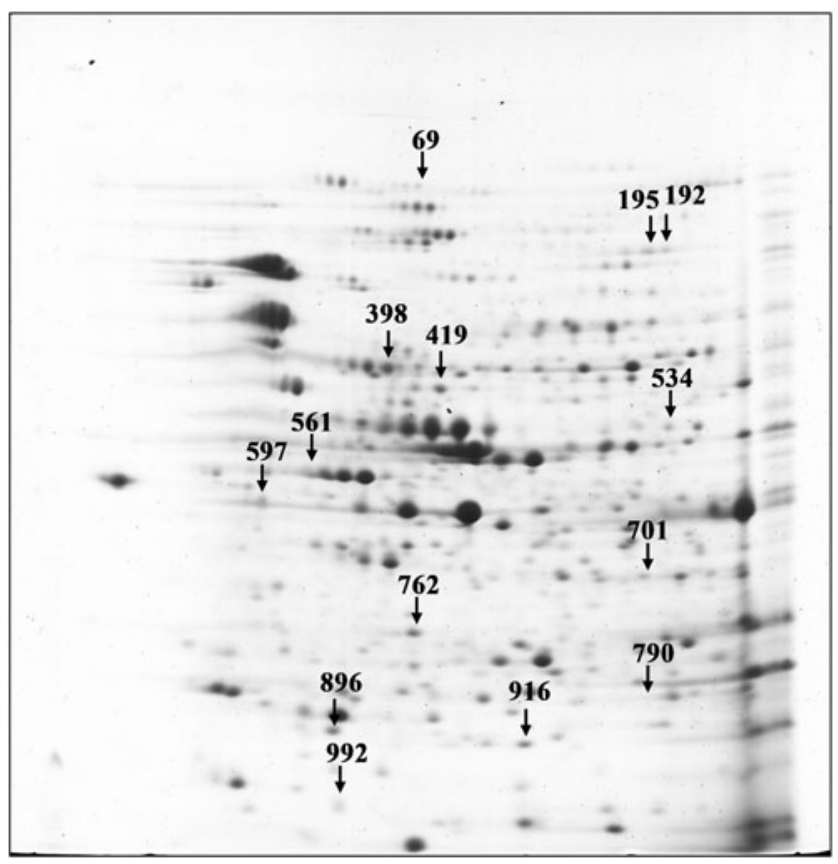

FIG. 3. 2-DE spot pattern of proteins from the host bacterial cells infected by phage SD1. The insets show differentially expressed proteins, which were further analyzed by MS (Fig. 4).

\section{Phage-infected E. coli characterization}

Protein samples from ESBL-producing E. coli C3570 host strain (condition 1) and host bacterial cells subjected to phage SD1 infection (condition 2) were distinctly separated and most formed a single spot on the 2-DE gel. There was a significant change in the 2-DE profile of the condition 2 when compared to the control (condition 1). In this sense, we performed an image analysis from three independent replicates for the two conditions under study using the SameSpots software (Nonlinear Dynamics Limited). The spots that presented significant differences between the two conditions (ANOVA $p$-value $\leq 0.05$ and a FDR $q$-value $\leq 0.05$ ) were physically located in the gels for excision and further analyzed by mass spectrometry (Fig. 3).

The nanoLC-MS/MS analysis detected 4 bacterial proteins that were significantly less expressed when the cells are infected by the virus, namely the Inorganic pyrophosphatase ( $19.7 \mathrm{kDa}$, sequence coverage of $48 \%$ ), the RNA polymerasebinding transcription factor DksA $(17.5 \mathrm{kDa}$, sequence coverage of $58 \%)$, the Aconitate hydratase B $(93.4 \mathrm{kDa}$, sequence coverage of $59 \%$ ), and D-ribose transporter RbsB (30.9 kDa, sequence coverage of 67\%) (Fig. 4).

On the contrary, 10 bacterial proteins were found upregulated after phage infection. These proteins have a sequence coverage ranging from $45 \%$ to $80 \%$ (Figs. 3 and 4 ). The proteins identified included Putative glucose-6phosphate1-epimerase $(32.6 \mathrm{kDa}, 45 \%)$, Aspartate ammonialyase $(52.3 \mathrm{kDa}, 48 \%)$, Two-component response regulator (27.2 kDa, 56\%), Phosphoglycerate kinase (PGK) (41 kDa, $57 \%$ ), Cysteine desulfurase IscS (45 kDa, 60\%), Peptidase PmbA (47.9 kDa, 62\%), Superoxide dismutase (SOD) (21.2 kDa, 62\%), Formate dehydrogenase-H (62.4 kDa, 65\%), ADP-L-glycero-D-manno-heptose-6-epimerase $\quad(34.8 \mathrm{kDa}$, $73 \%)$, and Formate dehydrogenase-H (62.4 kDa, 80\%).

Of the proteins showing an increase in their expression under phage infection, most were assigned as having functions in stress response. For example, the SOD (Ramos et al., 2016) as well as Formate dehydrogenase $H$ that acts as a stress protein and is involved in stress oxidative tolerance (Iwadate et al., 2017). Furthermore, Cysteine desulfurase IscS is other protein identified in the host bacterium $E$. coli with an increased expression under phage infection stress. This protein functions as a selenium delivery protein in the pathway for the biosynthesis of selenophosphate (Schwartz et al., 2000).

\begin{tabular}{|c|c|c|c|c|c|c|c|c|c|}
\hline${ }^{\mathrm{a}}$ Spot & $\begin{array}{l}\text { ANOVA (p- } \\
\text { value) }\end{array}$ & FDR (q-value) & Fold & Protein & Accession number & Species & Mw (Da) & Score & $\begin{array}{c}\text { MS coverage } \\
(\%)\end{array}$ \\
\hline 69 & 0.012 & 0.021 & -0.72 & Aconitate hydratase $\mathrm{B}$ & A0A0E0Y3T2_ECO1C & E. coli & 93439 & 2474 & 59 \\
\hline 192 & 0.016 & 0.024 & 5.8 & Formate dehydrogenase-H & A0A0E0Y568_ECO1C & E. coli & 62423 & 8657 & 80 \\
\hline 195 & 0.035 & 0.039 & 5.4 & Formate dehydrogenase-H & A0A0E0Y568_ECO1C & E. coli & 62423 & 2174 & 65 \\
\hline 398 & 0.005 & 0.012 & 1.6 & Aspartate ammonia-lyase & A0A0E0Y4Z5_ECO1C & E. coli & 52323 & 3467 & 48 \\
\hline 419 & 0.013 & 0.021 & 2.1 & Peptidase PmbA & A0A0E0Y6B7_ECO1C & E. coli & 47953 & 2191 & 62 \\
\hline 534 & 0.034 & 0.039 & 2.1 & Cysteine desulfurase IscS & A0A0E0XW33_ECO1C & E. coli & 45061 & 2440 & 60 \\
\hline 561 & $5,577 \mathrm{e}-004$ & 0.004 & 1.8 & Phosphoglycerate kinase & A0A0E0XWD2_ECO1C & E. coli & 41093 & 2378 & 57 \\
\hline 597 & 0.014 & 0.022 & 2.5 & $\begin{array}{c}\text { ADP-L-glycero-D- } \\
\text { manno-heptose-6- } \\
\text { epimerase }\end{array}$ & A0A0E0XVX3_ECO1C & E. coli & 34871 & 2412 & 73 \\
\hline 701 & 0.001 & 0.005 & 2.2 & $\begin{array}{l}\text { Putative glucose-6- } \\
\text { phosphate 1-epimerase }\end{array}$ & A0A0E0Y1Q9_ECO1C & E. coli & 32652 & 1027 & 45 \\
\hline 762 & $7,459 \mathrm{e}-004$ & 0.004 & 2.2 & $\begin{array}{l}\text { Two-component response } \\
\text { regulator }\end{array}$ & A0A0E0Y7R0_ECO1C & E. coli & 27275 & 1197 & 56 \\
\hline 790 & 0.005 & 0.012 & -0.53 & D-ribose transporter RbsB & A0A0E0Y7X2_ECO1C & E. coli & 30919 & 2232 & 67 \\
\hline 896 & $7,250 \mathrm{e}-005$ & 0.001 & -2.2 & $\begin{array}{c}\text { Inorganic } \\
\text { pyrophosphatase }\end{array}$ & A0A0E0Y4W1_ECO1C & E. coli & 19719 & 967 & 48 \\
\hline 916 & 0.001 & 0.005 & 2.01 & Superoxide dismutase & A0A0E0XZ00_ECO1C & E. coli & 21253 & 839 & 62 \\
\hline 992 & 0.036 & 0.041 & -0.41 & $\begin{array}{l}\text { RNA polymerase-binding } \\
\text { transcription factor DksA }\end{array}$ & A0A0E0Y7A7_ECO1C & E. coli & 17517 & 995 & 58 \\
\hline
\end{tabular}

${ }^{a}$ Spots are shown in Fig. 3; MW, molecular weight; MS coverage, percentage of amino acids in sequence matched by peptides detected by mass spectrometry.

FIG. 4. Differentially expressed proteins identified in the proteome of the host bacterial cells infected by phage SD1. Dark and light shading are used to facilitate data analysis through a gradient proportional to the fold change. ${ }^{a}$ Spots are shown in Figure 3; MW, molecular weight; MS coverage, percentage of amino acids in sequence matched by peptides detected by mass spectrometry. 
In addition, the PGK is a multifunctional enzyme that is involved in stress tolerance. The PGK is a glycolytic enzyme that catalyzes one of the two ATP-producing reactions in the glycolytic pathway, through the conversion of 1,3bisphosphoglycerate to 3-phosphoglycerate (Rojas-Pirela et al., 2020). The level of expression of this protein was increased during host bacterium infection by the phage SD1. Aspartate ammonia-lyase belongs to the family of lyases, which has catalytic activity by catalyzing the reversible conversion of L-aspartic acid to fumarate and ammonia (Rudolph and Fromm, 1971), and Peptidase PmbA has a metallopeptidase activity and is involved in the regulation of posttranscriptional activity during stress condition (Chandrasekhar et al., 2014); both are enzymes with increased expression upon infection of $E$. coli by phage SD1.

Thus, an overexpression in the levels of the putative glucose6-phosphate1-epimerase (catalytic activity) (Wurster and Hess, 1973), ADP-L-glycero-D-manno-heptose-6-epimerase (catalyzes the interconversion between ADP-D-glycero-betaD-manno-heptose and ADP-L-glycero-beta-D-manno-heptose via an epimerization at carbon 6 of the heptose) (Morrison and Tanner, 2007), and the two-component response regulator (it is a system that detect and respond to changes in many adverse environmental conditions such as oxidative stress) (Stock et al., 2000) levels was also noted during infection with the SD1 phage.

\section{Discussion}

This study assessed the proteome of three lytic bacteriophages SD1, SD2, and SD3 as well the differentially expressed proteins of their host strain extended spectrum B-lactamase-producing $E$. coli $\mathrm{C} 3570$ when infected by SD1 bacteriophage.

\section{Phage proteome}

The SD1 and SD2 phages share with the SH7 phage the same sizes of the following structural proteins: Major capsid protein $(56.5 \mathrm{kDa})$, Tail sheath monomer $(72.5 \mathrm{kDa})$, and the RNA polymerase ADP-ribosylase (76.2 kDa) (Hamdi et al., 2017). Interestingly, other than the phage SD1 and SD2 structural proteins, RNA polymerase ADP-ribosylase was determined with a relatively high sequence coverage value (43\%), which corresponds to an enzyme not usually present in the phage structure. The RNA polymerase ADP-ribosylase was also detected by mass spectrometry in SH7 and AR1 phages (Hamdi et al., 2017; Liao et al., 2011).

The ADP-ribosylase targets host RNA polymerase, and it is not essential for phage development (Goff and Setzer, 1980; Wilkens et al., 1997). Thus, it is possible that this protein was identified in our proteome data due to copurification with the phage particles (Goff and Setzer, 1980; Wilkens et al., 1997). The increase in gene expression after phage infection is under the control of ADP-ribosylation of RNA polymerase. However, the presence of this enzyme is not necessary for the phage development, but it plays an important role in shutting off host transcription; it is a virion component incorporated into the phage head.

While for phage SD2, the difference is obvious in the size of these two proteins: Putative long tail fiber, this protein is present in two alternative forms $(49.6,136.5 \mathrm{kDa})$, and Prohead core scaffold protein $(29.5 \mathrm{kDa})$. However, SH7 proteome characterization showed that the two previously mentioned proteins have the following sizes 140 and $16 \mathrm{kDa}$. The SD2 phage also differs from SH6 phage by the Portal protein size (Hamdi et al., 2017).

The major difference between the proteome of phages SD2 and vB_Eco4M-7, which was previously described by Necel et al., 2020, was the protein size. Nevertheless, this study showed that there is a correspondence in the identified proteins of these two phages. Citing the SD2 identified sizes: Tail sheath protein $(72.5 \mathrm{kDa})$, Portal protein $(60.4 \mathrm{kDa})$, Baseplate wedge subunit $(37.6 \mathrm{kDa})$, and Prohead core scaffold protein $(29.5 \mathrm{kDa})$. However, vB_Eco4M-7 values were as follows: $54.8,88.7,12.8$, and $41.7 \mathrm{kDa}$, respectively. On the contrary, the results obtained in this work were different to those reported by $\mathrm{Xu}$ et al., 2018, SD2 and vB_EcoS-B2 phages have one single common protein but with different size. For phage SD2, the Putative tail fiber protein presented $54.2 \mathrm{kDa}$ and phage vB_EcoS-B2 presented $125.8 \mathrm{kDa}(\mathrm{Xu}$ et al., 2018).

For phage SD3, the results of the Major capsid protein $(37.7 \mathrm{kDa})$ are in agreement with the data described by Yazdi et al., 2020, who reported a Major capsid protein of VB_EcoS-Golestan infecting multidrug-resistant $E$. coli with a similar size. In addition, the Putative major head protein $(37.8 \mathrm{kDa})$ reassembles with that of vB_EcoS-B2 (Xu et al., 2018). On the contrary, the SD3 and vB_EcoS-B2 phages have another common protein, but with different size. For phage SD3, the Putative tail fiber protein $(54.1 \mathrm{kDa})$ and the Structural protein $(50.2 \mathrm{kDa})$ had different sizes when compared to the phage vB_EcoS-B2 counterparts, 125.8 and $130.5 \mathrm{kDa}$, respectively (Xu et al., 2018).

The comparison between the structure proteins identified of the SD3 phage and that of vB Ec4M-7 phage showed a similarity of one protein with only a difference in protein size. The tail sheath monomer is the only common protein between SD3 and vB Ec4M-7 phages (Necel et al., 2020). Again, the only difference is in the protein size. The protein of SD3 phage had the size of $72.5 \mathrm{kDa}$, unlike vB Ec4M-7 phage that presented $54.8 \mathrm{kDa}$. The current study indicates that our results are in accordance with the previous studies. In general, the phages share the same proteins, presenting some important differences regarding its size.

The SD3 phage has two alternative forms for the Major capsid protein 37.7 and $56.5 \mathrm{kDa}$. The second form is like that of SH7 phage (Hamdi et al., 2017). Also, they have in common the Tail sheath monomer $(72.5 \mathrm{kDa})$, while they have another common protein but with different size. In SH7 phage, we find the Putative baseplate wedge tail fiber connector $(23 \mathrm{kDa})$, but this value is different in SD3 phage $(30.4 \mathrm{kDa})$.

The identification of two or more alternative forms for a protein can be due to the separation of different subunits of the same protein. These subunits are widely distributed on the gel and can be linked by covalent or noncovalent bonds resulting in the formation of a large protein (Ribeiro et al., 2020; Stone et al., 2019). For example, capsids are protein shells that surround and protect the viral genome. Capsid proteins often self-assemble with a quasi-equivalent arrangement of individual subunit. The capsid subunits use similar interactions throughout the assembly (Fokine and Rossmann, 2014; Stone et al., 2019).

For the phage SD3, as reported in the results section, we found two alternative forms of the Major capsid protein 
(56.5 and $37.7 \mathrm{kDa})$. Possibly, these subunits are parts of a bigger protein. Our results are in agreement with Fokine and Rossmann, 2014, and Stone et al., 2019, who demonstrated that the major capsid protein is a set of subunits arranged and linked by hydrogen bonds and salt bridges, which stabilize intracapsomeric interactions. So, these noncovalent interactions between the Major capsid protein subunits provide rigidity of the protein structure (Fokine and Rossmann, 2014; Ross et al., 2005; Stone et al., 2019).

Furthermore, bacteriophage tails (long tail fiber and short tail fiber) are fascinating molecular machines created to recognize the host cells, penetrate the cell envelope barrier, and deliver DNA into the cytoplasm (Fokine and Rossmann, 2014). The tail fibers are a complex protein structure that functions at the beginning of the infection process (Hyman and van Raaij, 2018). For SD2 proteins, the Putative long tail fiber was identified with two molecular masses of 49.9 and $136.5 \mathrm{kDa}$, which is in accordance with the results of Bishop et al., 1974. The putative long tail fiber protein is a large protein; its assembly takes place by noncovalent bonds between structural subunits, suggesting a rigid joining and structure stability.

In addition, Arnaud et al. (2017) demonstrated that two forms of tail tube protein were detected in E. coli T5 phage. This result is in accordance with our data as two forms of tail tube protein were found with two different sizes (17.1 and $18.3 \mathrm{kDa}$ ). According to the works of Langlois et al., 2015, and Špakova et al., 2019, the Tail tube protein is constituted by stacked rings of subunits and these subunits are connected by stable hydrogen bonds. This demonstrates that the two forms are two subunits interconnected by hydrogen bonds to form a bigger molecule of tail tube protein.

Our results strongly suggest that these three proteins that presented two alternative forms (Major capsid protein, the Putative long tail fiber, and the Tail tube protein) are part of bigger proteins stabilized by noncovalent interactions, which split into minor subunits. In fact, in the 2-DE analysis, the Major capsid protein, the Putative long tail fiber, and the Tail tube protein are three structural proteins, of which none resolved into a single discreet spot (Roberts et al., 2004). Obtaining two alternative forms of each of these three proteins may be due to posttranslational modifications, this hypothesis in agreement with the previous results of Martin et al., 1976, and Roberts et al., 2004.

Among the structural proteins identified in phage SD3, we found the Peptidase S74 (101.9 kDa). This protein is a chaperone of Endosialidase, which acts as a tail spike protein. This chaperone is responsible for the host polysialic acid capsule recognition, binding and degradation activity (Stummeyer et al., 2005).

The proteome characterization of SD1, SD2, and SD3 phages identified a variety of tail fiber proteins (Putative tail fiber proteins, Putative baseplate wedge tail fiber connector, Putative baseplate wedge subunit and tail pin, Tail tube protein, and Putative long tail fiber). Tail fibers in the phage tail play a primordial role in the initiation of the phage coupling with its bacterial receptors. In addition, these fibers have a role in the host specificity (Li et al., 2016; Yazdi et al., 2020). It is only after successful adsorption that a phage is properly posed to release its genetic material into the cytoplasm of the host cell, in which the viral infectious cycle can continue. Completion of adsorption step is the key signal of DNA injection (McPartland and Rothman-Denes, 2009).
Before phage genomic material delivery by the Tail Sheath protein, there will be attachment and coupling step with the bacterial receptors located in the host outer membrane envelope. This fixation is provided by phage basal plate that is decorated by some tail fiber proteins (Arisaka et al., 2016). Based on our results, the tail sheath protein presented a high sequence coverage (57\%). This protein is the main element that allows the delivery and release of the genetic material of the phage through the host cell envelope, in other words, it is the way of the establishment of a direct connection between phage-host also as an event signaling for DNA injection (Kurochkina et al., 2018; McPartland and RothmanDenes, 2009).

Thus, the Prohead core scaffold protein has an outer shell, which is formed by the major capsid protein, and it has an inner core made from scaffold proteins. Usually, the Prohead has a protease, which is activated during the maturation of the capsid to destroy the inner core and free up space for the genome (Fokine and Rossmann, 2016). While the portal protein multimerizes as a single ring-shaped homododecamer arranged around a central channel by forming the portal vertex of the capsid, this protein has different critical roles in head assembly, viral DNA genome packaging, neck/tail attachment, and genome ejection through host cell envelope (Hua et al., 2014; Rao and Feiss, 2008).

\section{Cellular response to phage infection}

The phage infection stress changed the expression of several E. coli proteins. A downregulated expression of Aconitate hydratase B (fold of -0.72), D-ribose transporter RbsB (fold of -0.53), Inorganic pyrophosphatase (fold of -2.2), and RNA polymerase binding transcription factor DKsA (fold of -0.41) was noticed.

The Aconitate hydratase B in E. coli is involved in the catabolism of short-chain fatty acids via the tricarboxylic acid and the 2-methylcitrate cycle I. This protein catalyzes the reversible isomerization of citrate to isocitrate via cisaconitate. Also catalyzes the hydration of 2-methyl-cisaconitate to yield (2R,3S)-2-methylisocitrate (Tang et al., 2002). Several studies demonstrated that the Aconitate hydratase B serve as a protective buffer against the basal level of oxidative stress that accompanies aerobic growth by acting as a sink for reactive oxygen species and by modulating translation of the sodA transcript (Lopez-Campistrous et al., 2005; Tang et al., 2002; Tonella et al., 2001; Yan et al., 2002).

D-ribose transporter RbsB is a ribose-binding protein, involved in molecules transporter. Similarly to our results, there was a dramatic reduction in the level of $\mathrm{RbsB}$ in Bacillus subtilis under phage $\varphi 29$ infection (Mojardín and Salas, 2016). D-Ribose is one of the metabolites that bacteria can actively transport into the cell to use as carbon and energy source. Previously reported work demonstrated that in phage infection stress, this protein was downregulated (Mojardín and Salas, 2016).

The microbial Inorganic pyrophosphatase plays a primordial role in macromolecular biosynthesis and is essential for the viability of E. coli (Triccas and Gicquel, 2001). This enzyme catalyzes hydrolysis of Inorganic pyrophosphate, Tripolyphosphate, and Tetrapolyphosphate (Josse, 1966). General oxidative stress did not increase the activity of the Inorganic pyrophosphatase in Mycobacterium tuberculosis 
in vitro (Triccas and Gicquel, 2001). But regarding the intracellular oxidative stress, it has resulted in a stable expression level of the Inorganic pyrophosphatase (Abu Kwaik, 1998).

This study demonstrated that this protein was specifically induced in response to the intracellular environment of that host. The decrease in expression of this protein under stress exerted during host viral infection (intracellular stress) was confirmed by other works (Abu Kwaik, 1998; Triccas and Gicquel, 2001). So, this may suggest that the Inorganic pyrophosphatase reacts only under conditions of intracellular stress.

In E. coli, DksA is a transcriptional regulator that modulates gene expression at the levels of transcription initiation and elongation (Haugen et al., 2008; Roghanian et al., 2015). RNA polymerase-binding transcription factor DksA was found downregulated in our study. It belongs to a family of proteins that can insert themselves into the two channels of RNAP. The best characterized system of DksA regulation is stress response (Kolmsee et al., 2011). DksA is a key player in bacterial survival under various environmental changes.

For example, DksA of Salmonella enterica is hypersusceptible to the bacteriostatic effects of nitric oxide free radicals and is attenuated in macrophage and murine models of infection (Henard and Vazquez-Torres, 2012). The Shigella flexneri DksA has decreased Hfq transcription, causing the loss of virulence (Sharma and Payne, 2006), and in E. coli, DksA has been shown to be important for survival of dehydration (Chen and Goulian, 2018). Again, various studies have shown that DksA provokes global changes in transcriptional expression in host cells under various stresses, such as nitrosative, oxidative, and nutrient stresses (Crawford et al., 2016; Holley et al., 2015). To our knowledge, no study has reported whether DksA contributes or not to defense of host bacterial cells against phage infection.

This study suggests that the downregulation of some bacterial proteins is necessary to promote a rapid change in host metabolism for an optimal viral development.

On the contrary, some key oxidative stress-related proteins were found upregulated after SD1 phage infection, namely SOD, Formate dehydrogenase-H, Cysteine desulfurase IscS, Aspartate ammonia-lyase, Peptidase PmbA, PGK, Putative glucose-6-phosphate 1-epimerase, ADP-L-glycero-D-mannoheptose-6-epimerase, and the two-component response regulator.

The SOD is an antioxidant enzyme involved in the defense mechanism against oxidative stress by catalyzing the dismutation of toxic superoxide anion radicals produced in stressed cells (Ramos et al., 2016; Schellhorn and Hassan, 1988). The increase in the expression of SOD during infection of $E$. coli by phage SD1 indicates that the host bacterial cells are under unfavorable and stressful conditions, which generate a state of oxidative stress. This suggests that the SOD protein is a putative marker for viral infection in bacteria.

Formate dehydrogenases are enzymes that catalyze the oxidation of formate to carbon dioxide coupled to NAD+ reduction into NADH (Savin and Tishkov, 2010). These enzymes act as stress proteins in pathogenic microorganisms such as E. coli (Colas des Francs-Small et al., 1993). The formate dehydrogenase- $\mathrm{H}$ is an enzyme detected in our host strain of E. coli that showed a very high level (sequence coverage of $80 \%$, fold of 5.8 ) of expression during stress induced by SD1 phage. This result is in agreement with the study carried out by Iwadate et al., 2017 who highlighted the role of formate dehydrogenase- $\mathrm{H}$ in contributing for the stationary phase oxidative stress tolerance in E. coli. In this sense, it is possible that the contribution of this protein for the oxidative stress tolerance generated the host bacteria cells following phage infection.

Cysteine desulfurase IscS produces sulfur and 1-alanine from 1-cysteine. This protein was involved in the recovery of [Fe-S] clusters (Ding et al., 2005; Schwartz et al., 2000). Oxidative stress leads to the formation of reactive oxygen species, hence cellular stress (Han and Lee, 2006). Maintaining cellular redox balance is found to be a process that involves molecules synthesized from reduced sulfur extracted from the environment. As other authors suggested that expression of IscS in E. coli protects against the denaturation of cytoplasmic proteins during oxidative stress (Dai and Outten, 2012; Fuentes et al., 2007). In this case, it can also be suggested that Cysteine desulfurase IscS is involved in the contribution of tolerance to oxidative stress caused by infection of phage SD1.

Another bacterial protein, which presented a high level of expression (sequence coverage of 57\%, fold of 1.8) under the stress of SD1 phage infection, is the PGK. This is a glycolytic enzyme that catalyzes one of the two ATP-producing reactions in the glycolytic pathway, through the conversion of 1,3-bisphosphoglycerate to 3-phosphoglycerate (RojasPirela et al., 2020). In E. coli, PGK has been cataloged as an enzyme that is part of a complexome, associated with proteins involved in glycolysis and the stress response (Joshi et al., 2016; Pan et al., 2011). The host bacteria E. coli underwent oxidative stress during the phage infection, and based on our results it can be deduced that PGK appears to be a potential candidate for increasing bacterial tolerance to stress exerted during viral infection.

Aspartate ammonia-lyase was also a protein found upregulated for condition 2. Aspartase belongs to the family of lyases, ammoniacal lyases, which cut carbon-nitrogen bonds. It is found in various bacteria, including E. coli. Aspartate ammonia lyase has catalytic activity by catalyzing the reversible conversion of $\mathrm{L}$-aspartic acid to fumarate and ammonia (Rudolph and Fromm, 1971). The Peptidase PmbA was another protein showed a notable change in its expression after exposure to stress condition through the presence of phage SD1 (sequence coverage of $62 \%$, fold of 2.1).

It has been shown previously that the Peptidase PmbA was downregulated in E. coli under stress conditions (Chandrasekhar et al., 2014). This result is in disagreement with our results that this protein increased the level of expression under phage infection. During stress, this protein was involved in the regulation of posttranscriptional activity (Chandrasekhar et al., 2014). So, we can only agree with the predicted function for peptidase PmbA during the E. coli stress mechanism.

Similarly, the two-component response regulator has also presented an increased expression. It is a two-component regulatory system that serves as a basic stimulus-response coupling mechanism to enable organisms especially in gramnegative bacteria (which in our case: $E$. coli) to detect and respond to changes in many adverse environmental conditions such as oxidative stress (Stock et al., 2000). During the 
infection process, bacteria encounter different strapping conditions, which cause a cellular imbalance that subsequently generates a state of oxidative stress. The two-component response regulator system pathway is a primary means of responding to external stimuli (Zheng et al., 2018).

Previous work has shown that this system in E. coli is involved in cellular adaptation to oxidative stress (Park et al., 2020; Zheng et al., 2019). So, this prompted us to admit the same suggestion about the role of the two-component response regulator system by adapting and increasing the tolerance of bacterial host cells of $E$. coli infected to oxidative stress generated during viral infection.

Finally, two other proteins were upregulated for condition 2, namely the ADP-L-glycero-D-manno-heptose-6epimerase (sequence coverage of $73 \%$, fold of 2.5 ) and the putative glucose-6-phosphate 1-epimerase (sequence coverage of $45 \%$, fold of 2.2 ).

Based on these findings, SD1 phage infection puts the host bacterium $E$. coli into a state of oxidative stress. To cope with oxidative stress, E. coli cells trigger rapid global responses designed to eliminate reactive oxygen species (ROS), repair oxidative damage, bypass damaged functions, and induce adapted metabolism, thus allowing the cells to persist under high ROS conditions. The bacterial cells response to stress is usually orchestrated by antioxidant defense mechanisms (Srivastava and Kumar, 2015). Proteomic analyses have further revealed that the level of antioxidant enzymes (SOD, Cysteine desulfurase IscS, and Formate dehydrogenase-H), the PGK, the Peptidase PmbA, and the two-component response regulator system is increased to have key regulatory functions in cellular detoxification of $E$. coli cells infected by the phage.

\section{Conclusion}

This study allowed us to get new insights into the proteome of three novel $E$. coli bacteriophages and the identification of important structural proteins for SD1-SD3 phages was accomplished. The proteome of each phage showed a different protein profile ( $\mathrm{Mw}$ and $\mathrm{pI}$ ) with common proteins, namely the Major capsid protein, Tail sheath monomer, and Capsid vertex protein. To better understand the cellular response of the host bacterium to the phage infection, a gel-based quantitative proteomics study was performed. Several bacterial proteins were found differentially expressed, particularly related to stress response. Antioxidant enzymes (SOD, Cysteine desulfurase IscS, and Formate dehydrogenase-H), the PGK, the Peptidase PmbA, and the two-component response regulator system seemed to be involved in oxidative stress tolerance during phage infection.

In general, these results indicate that $E$. coli bacterium undergoes oxidative stress. The knowledge of how the bacterium's proteome responds physiologically to phage infection stress, such as the increased expression of the antioxidant enzymes to tolerate the stress situation, can be an important step, preliminary though, for the better understanding of the mechanisms and interactions between bacteriophages and their hosts. Considering that antimicrobial resistance is increasing, while the rate of discovery of new antibiotics is decreasing, the identification and characterization of targetspecific bacteriophages take on special importance and raise some expectations to face a possible postantibiotic era.

\section{Author Disclosure Statement}

The authors declare that the research was conducted in the absence of any commercial or financial relationships that could be construed as a potential conflict of interest.

\section{Funding Information}

This work was supported by the Associate Laboratory for Green Chemistry-LAQV which is financed by national funds from FCT/MCTES (UIDB/50006/2020).

\section{References}

Abu Kwaik Y. (1998). Induced expression of the Legionella pneumophila gene encoding a 20-kilodalton protein during intracellular infection. Infect Immun 66, 203-212.

Arisaka F, Yap ML, Kanamaru S, and Rossmann MG. (2016). Molecular assembly and structure of the bacteriophage T4 tail. Biophys Rev 8, 385-396.

Arnaud CA, Effantin G, Vives C, et al. (2017). Bacteriophage T5 tail tube structure suggests a trigger mechanism for Siphoviridae DNA ejection. Nat Commun 8, 1953.

Ben Said L, Jouini A, Alonso CA, et al. (2016). Characteristics of extended-spectrum $\beta$-lactamase (ESBL)- and pAmpC beta-lactamase-producing Enterobacteriaceae of water samples in Tunisia. Sci Total Environ 550, 1103-1109.

Ben Sallem R, Ben Slama K, Estepa V, et al. (2015). Detection of CTX-M-15-producing Escherichia coli isolates of lineages ST410-A, ST617-A and ST354-D in faecal samples of hospitalized patients in a Mauritanian hospital. J Chemother 27, 114-116.

Ben Yahia H, Chairat S, Gharsa H, et al. (2020). First report of KPC-2 and KPC-3-producing Enterobacteriaceae in wild birds in Africa. Microb Ecol 79, 30-37.

Bishop RJ, Conley MP, and Wood WB. (1974). Assembly and attachment of bacteriophage T4 tail fibers. J Supramol Struct 2, 196-201.

Blasdel BG, Chevallereau A, Monot M, Lavigne R, and Debarbieux L. (2017). Comparative transcriptomics analyses reveal the conservation of an ancestral infectious strategy in two bacteriophage genera. ISME J 11, 1988-1996.

Bolocan AS, Callanan J, Forde A, Ross P, and Hill C. (2016). Phage therapy targeting Escherichia coli-A story with no end? FEMS Microbiol Lett 363, fnw256.

Boulanger P. (2009). Purification of bacteriophages and SDSPAGE analysis of phage structural proteins from ghost particles. Methods Mol Biol 502, 227-238.

Brötz-Oesterhelt H, Bandow JE, and Labischinski H. (2005). Bacterial proteomics and its role in antibacterial drug discovery. Mass Spectrom Rev 24, 549-565.

Chandrasekhar K, Sreedevi B, Sreevani S, et al. (2014). Characterisation and structural dynamics of differentially expressed proteins of probiotic Escherichia coli Nissle 1917 in response to Cocos nucifera Sap. J Proteom Bioinform 7, 179-185.

Chen AI, and Goulian M. (2018). A network of regulators promotes dehydration tolerance in Escherichia coli. Environ Microbiol 20, 1283-1295.

Chibani-Chennoufi S, Dillmann M-L, Marvin-Guy L, RamiShojaei S, and Brüssow H. (2004). Lactobacillus plantarum bacteriophage LP65: A new member of the SPO1-like genus of the family Myoviridae. J Bacteriol 186, 7069-7083.

Colas Des Francs-Small C, Ambard-Bretteville F, Small ID, and Rémy R. (1993). Identification of a major soluble protein 
in mitochondria from nonphotosynthetic tissues as NADdependent formate dehydrogenase. Plant Physiol 102, 11711177.

Crawford MA, Henard CA, Tapscott T, Porwollik S, Mcclelland M, and Vazquez-Torres A. (2016). DksAdependent transcriptional regulation in Salmonella experiencing nitrosative stress. Front Microbiol 7, 444.

Dai Y, and Outten FW. (2012). The E. coli SufS-SufE sulfur transfer system is more resistant to oxidative stress than IscSIscU. FEBS Lett 586, 4016-4022.

Dalmasso M, Strain R, Neve H, et al. (2016). Three new Escherichia coli phages from the human gut show promising potential for phage therapy. PLoS One 11, e0156773.

Ding H, Harrison K, and Lu J. (2005). Thioredoxin reductase system mediates iron binding in IscA and iron delivery for the iron-sulfur cluster assembly in IscU. J Biol Chem 280, 30432-30437.

Fokine A, and Rossmann MG. (2014). Molecular architecture of tailed double-stranded DNA phages. Bacteriophage 4, e28281.

Fokine A, and Rossmann MG. (2016). Common evolutionary origin of procapsid proteases, phage tail tubes, and tubes of bacterial type VI secretion systems. Structure 24, 1928-1935.

Fuentes DE, Fuentes EL, Castro ME, et al. (2007). Cysteine metabolism-related genes and bacterial resistance to potassium tellurite. J Bacteriol 189, 8953-8960.

Goff CG, and Setzer J. (1980). ADP-ribosylation of Escherichia coli RNA polymerase is non essential for bacteriophage T4 development. J Virol 33, 547-549.

Hamdi S, Rousseau GM, Labrie SJ, et al. (2016). Characterization of five podoviridae phages infecting Citrobacter freundii. Front Microbiol 7, 1023.

Hamdi S, Rousseau GM, Labrie SJ, et al. (2017). Characterization of two polyvalent phages infecting Enterobacteriaceae. Sci Rep 7, 40349.

Han M-J, and Lee SY. (2006). The Escherichia coli proteome: past, present, and future prospects. Microbiol Mol Biol Rev 70, 362-439.

Haugen SP, Ross W, and Gourse RL. (2008). Advances in bacterial promoter recognition and its control by factors that do not bind DNA. Nat Rev Microbiol 6, 507-519.

Henard CA, and Vazquez-Torres A. (2012). DksA-dependent resistance of Salmonella enterica serovar Typhimurium against the antimicrobial activity of inducible nitric oxide synthase. Infect Immun 80, 1373-1380.

Holley CL, Zhang X, Fortney KR, et al. (2015). DksA and (p)ppGpp have unique and overlapping contributions to Haemophilus ducreyi pathogenesis in humans. Infect Immun 83, 3281-3292.

Hua Y, An X, Pei G, et al. (2014). Characterization of the morphology and genome of an Escherichia coli podovirus. Arch Virol 159, 3249-3256.

Hyman P, and Van Raaij M. (2018). Bacteriophage T4 long tail fiber domains. Biophys Rev 10, 463-471.

Iwadate Y, Funabasama N, and Kato J-I. (2017). Involvement of formate dehydrogenases in stationary phase oxidative stress tolerance in Escherichia coli. FEMS Microbiol Lett 364, fnx193.

Joshi R, Karan R, Singla-Pareek SL, and Pareek A. (2016). Ectopic expression of Pokkali phosphoglycerate kinase-2 (OsPGK2-P) improves yield in tobacco plants under salinity stress. Plant Cell Rep 35, 27-41.

Josse J. (1966). Constitutive inorganic pyrophosphatase of Escherichia coli. 1. Purification and catalytic properties. J Biol Chem 241, 1938-1947.
Kolmsee T, Delic D, Agyenim T, Calles C, and Wagner R. (2011). Differential stringent control of Escherichia coli rRNA promoters: Effects of ppGpp, DksA and the initiating nucleotides. Microbiology 157, 2871-2879.

Kurochkina LP, Semenyuk PI, Sykilinda NN, and Miroshnikov KA. (2018). The unique two-component tail sheath of giant Pseudomonas phage PaBG. Virology 515, 46-51.

Langlois C, Ramboarina S, Cukkemane A, et al. (2015). Bacteriophage SPP1 tail tube protein self-assembles into $\beta$-structure-rich tubes. J Biol Chem 290, 3836-3849.

Li E, Wei X, Ma Y, et al. (2016). Isolation and characterization of a bacteriophage phiEap-2 infecting multidrug resistant Enterobacter aerogenes. Sci Rep 6, 28338.

Liao W-C, Ng W, Lin IH, Syu W, Jr., Liu T-T, and Chang C-H. (2011). T4-like genome organization of the Escherichia coli O157:H7 lytic phage AR1. J Virol 85, 6567-6578.

Lopez-Campistrous A, Semchuk P, Burke L, et al. (2005). Localization, annotation, and comparison of the Escherichia coli K-12 proteome under two states of growth. Mol Cell Proteomics 4, 1205-1209.

Martin DT, Adair CA, and Ritchie DA. (1976). Polypeptides specified by bacteriophage T1. J Gen Virol 33, 309-319.

Mcpartland J, and Rothman-Denes LB. (2009). The tail sheath of bacteriophage N4 interacts with the Escherichia coli receptor. J Bacteriol 191, 525-532.

Mojardín L, and Salas M. (2016). Global transcriptional analysis of virus-host interactions between phage $\varphi 29$ and Bacillus subtilis. J Virol 90, 9293-9304.

Morrison JP, and Tanner ME. (2007). A two-base mechanism for Escherichia coli ADP-L-glycero-D-manno-heptose 6epimerase. Biochemistry 46, 3916-3924.

Necel A, Bloch S, Nejman-Faleńczyk B, et al. (2020). Characterization of a bacteriophage, vB_Eco4M-7, that effectively infects many Escherichia coli O157 strains. Sci Rep $10,3743$.

Odenthal S, Akineden Ö, and Usleber E. (2016). Extendedspectrum $\beta$-lactamase producing Enterobacteriaceae in bulk tank milk from German dairy farms. Int J Food Microbiol 5, 72-78.

Pan JY, Wu H, Liu X, et al. (2011). Complexome of Escherichia coli cytosolic proteins under normal native conditions. Mol Biosyst 7, 2651-2663.

Park SJ, Lim S, and Choi JI. (2020). Improved tolerance of Escherichia coli to oxidative stress by expressing putative response regulator homologs from Antarctic bacteria. J Microbiol 58, 131-141.

Poeta P, Radhouani H, Pinto L, et al. (2009). Wild boars as reservoirs of extended-spectrum beta-lactamase (ESBL) producing Escherichia coli of different phylogenetic groups. J Basic Microbiol 49, 584-588.

Ramos S, Silva N, Hebraud M, et al. (2016). Proteomics for drug resistance on the food chain? Multidrug-resistant Escherichia coli proteomes from slaughtered pigs. OMICS 20, 362-374.

Rao V, and Feiss M. (2008). The bacteriophage DNA packaging motor. Annu Rev Genet 42, 647-681.

Ribeiro M, Freitas M, Domínguez-Perles R, Barros A, FerreiraCardoso J, and Igrejas G. (2020). Nutriproteomics survey of sweet chestnut (Castanea sativa Miller) genetic resources in Portugal. Food Biosci 36, 100622.

Ribeiro M, Nunes FM, Guedes S, et al. (2015). Efficient chemoenzymatic gluten detoxification: Reducing toxic epitopes for celiac patients improving functional properties. Sci Rep 5, 18041 . 
Roberts MD, Martin NL, and Kropinski AM. (2004). The genome and proteome of coliphage T1. Virology 318, 245266.

Roghanian M, Zenkin N, and Yuzenkova Y. (2015). Bacterial global regulators DksA/ppGpp increase fidelity of transcription. Nucleic Acids Res 43, 1529-1536.

Rojas-Pirela M, Andrade-Alviarez D, Rojas V, et al. (2020). Phosphoglycerate kinase: Structural aspects and functions, with special emphasis on the enzyme from Kinetoplastea. Open Biol 10, 200302.

Ross PD, Cheng N, Conway JF, et al. (2005). Crosslinking renders bacteriophage HK97 capsid maturation irreversible and effects an essential stabilization. EMBO J 24, 1352-1363.

Rudolph FB, and Fromm HJ. (1971). The purification and properties of aspartase from Escherichia coli. Arch Biochem Biophys 147, 92-98.

Savalia D, Westblade L, Goel M, et al. (2008). Genomic and proteomic analysis of phiEco32, a novel Escherichia coli bacteriophage. J Mol Biol 377, 774-789.

Savin SS, and Tishkov VI. (2010). Assessment of formate dehydrogenase stress stability in vivo using inactivation by hydrogen peroxide. Acta Naturae 2, 97-102.

Schellhorn HE, and Hassan HM. (1988). Response of hydroperoxidase and superoxide dismutase deficient mutants of Escherichia coli K-12 to oxidative stress. Can J Microbiol 34, 1171-1176.

Schwartz CJ, Djaman O, Imlay JA, and Kiley PJ. (2000). The cysteine desulfurase, IscS, has a major role in in vivo $\mathrm{Fe}-\mathrm{S}$ cluster formation in Escherichia coli. Proc Natl Acad Sci U S A 97, 9009-9014.

Sharma AK, and Payne SM. (2006). Induction of expression of hfq by DksA is essential for Shigella flexneri virulence. Mol Microbiol 62, 469-479.

Špakova A, Šimoliūnas E, Batiuškaitė R, Pajeda S, Meškys R, and Petraitytè-Burneikienè R. (2019). Self-assembly of tail tube protein of bacteriophage $\mathrm{vB}$ _EcoS_NBD2 into extremely long polytubes in E. coli and $S$. cerevisiae. Viruses 11,208

Srivastava KK, and Kumar R. (2015). Stress, oxidative injury and disease. Indian J Clin Biochem 30, 3-10.

Stock AM, Robinson VL, and Goudreau PN. (2000). Twocomponent signal transduction. Annu Rev Biochem 69, 183215.

Stone NP, Demo G, Agnello E, and Kelch BA. (2019). Principles for enhancing virus capsid capacity and stability from a thermophilic virus capsid structure. Nat Commun 10, 4471.

Stummeyer K, Dickmanns A, Mühlenhoff M, Gerardy-Schahn R, and Ficner R. (2005). Crystal structure of the polysialic acid-degrading endosialidase of bacteriophage K1F. Nat Struct Mol Biol 12, 90-96.

Tang Y, Quail MA, Artymiuk PJ, Guest JR, and Green J. (2002). Escherichia coli aconitases and oxidative stress: Posttranscriptional regulation of sodA expression. Microbiology 148, 1027-1037.

Tonella L, Hoogland C, Binz PA, Appel RD, Hochstrasser DF, and Sanchez JC. (2001). New perspectives in the Escherichia coli proteome investigation. Proteomics 1, 409-423.

Törneke K, Torren-Edo J, Grave K, and Mackay D. (2015). The management of risk arising from the use of antimicrobial agents in veterinary medicine in EU/EEA countries-A review. J Vet Pharmacol Ther 38, 519-528.

Triccas JA, and Gicquel B. (2001). Analysis of stress- and host cell-induced expression of the Mycobacterium tuberculosis inorganic pyrophosphatase. BMC Microbiol 1, 3.
Wilkens K, Tiemann B, Bazan JF, and Rüger W. (1997). ADPribosylation and early transcription regulation by bacteriophage T4. Adv Exp Med Biol 419, 71-82.

Wommack KE, and Colwell R. (2000). Virioplankton: Viruses in aquatic ecosystems. Microbiol Mol Biol Rev 64, 69-114.

Wurster B, and Hess B. (1973). Enzyme-catalyzed anomerization of D-glucose-6-phosphate. FEBS Lett 38, 33-36.

Xu Y, Yu X, Gu Y, Huang X, Liu G, and Liu X. (2018). Characterization and genomic study of phage vB_EcoS-B2 infecting multidrug-resistant Escherichia coli. Front Microbiol 9, 793.

Yan JX, Devenish AT, Wait R, Stone T, Lewis S, and Fowler S. (2002). Fluorescence two-dimensional difference gel electrophoresis and mass spectrometry based proteomic analysis of Escherichia coli. Proteomics 2, 1682-1698.

Yazdi M, Bouzari M, Ghaemi EA, and Shahin K. (2020). Isolation, characterization and genomic analysis of a novel bacteriophage VB_EcoS-Golestan infecting multidrugresistant Escherichia coli isolated from urinary tract infection. Sci Rep 10, 7690.

Zheng C, Li L, Ge H, et al. (2018). Role of two-component regulatory systems in the virulence of Streptococcus suis. Microbiol Res 214, 123-128.

Zheng J, Tang C, Deng C, and Wang Y. (2019). Involvement of a response regulator VdSsk1 in stress response, melanin biosynthesis and full virulence in Verticillium dahliae. Front Microbiol 10, 606.

\section{Address correspondence to:} Gilberto Igrejas, PhD Department of Genetics and Biotechnology University of Trás-os-Montes and Alto Douro Vila Real 5000-801 Portugal

E-mail: gigrejas@utad.pt

$\begin{aligned} & \text { Abbreviations Used } \\ & \text { ANOVA }=\text { analysis of variance } \\ & \mathrm{BHI}=\text { brain-heart infusion } \\ & \mathrm{CHAPS}= 3 \text {-[(3-cholamidopropyl) } \\ & \text { dimethylammonio]-1-propanesulfonate } \\ & \mathrm{DMSO}= \text { dimethylsulfoxide } \\ & \mathrm{DTT}= 1, \text { 4-dithiothreitol } \\ & \mathrm{ESBL}= \text { extended spectrum } \beta \text {-lactamases } \\ & \mathrm{FDR}= \text { false discovery rate } \\ & \mathrm{FTMS}= \text { Fourier transform mass spectrometry } \\ & \mathrm{IEF}= \text { isoelectric focusing } \\ & \mathrm{IPG}= \text { immobilized pH gradient } \\ & \mathrm{MW}= \text { molecular weight } \\ & \text { nanoLC-MS/MS }= \text { nanoscale liquid chromatography } \\ & \text { coupled to tandem mass spectrometry } \\ & \mathrm{OD}= \text { optical density } \\ & \mathrm{PCR}= \text { polymerase chain reaction } \\ & \mathrm{PEG}= \text { polyethylene glycol } \\ & \mathrm{PGK}= \text { Phosphoglycerate kinase } \\ & \mathrm{ROS}= \text { reactive oxygen species } \\ & \mathrm{SDS}= \text { sodium dodecyl sulfate } \\ & \mathrm{SDS}-\mathrm{PAGE}= \text { SDS-polyacrylamide gel electrophoresis } \\ & \mathrm{SOD}= \text { Superoxide dismutase } \\ & \mathrm{TCA}= \text { trichloroacetic acid } \\ & \mathrm{TFA}= \text { trifluoroacetic acid } \\ &\end{aligned}$

